\title{
PARA UMA CRIAÇÃO (EM) COMUM: PERSPETIVA SOCIO-CONSTRUTIVISTA PARA A CRIAÇÃO COREOGRÁFICA EM CONTEXTOS EDUCATIVOS
}

FOR A COMMON CREATION: A SOCIO-CONSTRUCTIVE PERSPECTIVE FOR COREOGRAPHY IN EDUCATION

PARA UNA CREACIÓN COMÚN: UNA PERSPECTIVA SOCIO-CONSTRUCTIVA PARA LA CREACIÓN COREOGRÁFICA EN CONTEXTOS EDUCATIVOS

NETO, Ângelo Cid1 1

\section{RESUMO}

O presente texto coloca em diálogo os processos de ensino-aprendizagem com os processos de criação coregráfica em contextos educativos. No quadro teórico, estabeleceu-se um diálogo entre aspetos construtivistas da educação enunciados por Bruner e Vygotsky com o espetro didático-democrático proposto por Butterworth no campo da criação coreográfica. Importa entender como a Cultura faz parte da Educação e como a Colaboração pode ser um aspeto fundamental na criação artística em contexto educativo. Neste processo de equilíbrio, surgem duas forças personificadas pelos agentes professor-aluno e coreógrafo-intérprete. E é, na multiplicidade das suas formas e composições, que reside o núcleo deste texto.

Palavras-chave: Educação Artística. Dança. Colaboração. Métodos e processos coreográficos.

\section{ABSTRACT}

This paper explores the dialogue between learning processes and choreographic creation in educational contexts. In the theoretical framework, a dialogue was established between constructivist aspects of education enunciated by Bruner and Vygotsky with the didactic-democratic spectrum proposed by Butterworth in the field of choreographic creation. Thus, it is important to understand how Culture is part of Education and how Collaboration can be a fundamental aspect in artistic creation in an educational context. In this process of balance, two forces emerge, personified by the teacher-student and choreographerinterpreter. And it is in the multiplicity of forms and compositions that the core of this text is relies.

Keywords: Artistic Education. Dance. Collaboration. Choreographic processes.

\section{RESUMEN}

El presente texto coloca en dialogo los procesos de enseñanza - aprendizaje con los procesos de creación coreográfica en contextos educativos. En el cuadro teórico, se estableció un dialogo entre aspectos constructivistas de la educación enunciados por Bruner y Vygotsky con el espectro didáctico - democrático propuesto por Butterworth en el campo de la creación coreográfica. Importa entender como la Cultura hace parte de la Educación y como la Colaboración puede ser un aspecto fundamenta en la creación artística en contexto educativo. En este proceso de equilibrio, surgen dos fuerzas personificadas por los agentes profesor - alumno y coreógrafo - interprete. $\mathrm{Y}$ es, en la multiplicidad de las formas y composiciones que reside el núcleo de este texto.

Palabras clave: Educación artística. Danza. Colaboración. Procesos coreográficos.

\footnotetext{
${ }^{1}$ IE ULISBOA e CIEBA - Lisboa - Portugal.
} 


\section{A FERIDA DO ENCONTRO}

A educação artística é uma área de profundo interesse no que respeita às interações entre as esferas da educação e da arte. Nesta, sublinha-se a possibilidade do encontro das palavras educação e arte. Educação na sua origem latina educare derivada de ex (exterior) e ducere (guiar) pode ser livremente traduzida para "guiar para fora". A imagem de extração ecoa no pensamento traduzido por este texto respeitante à educação contemporânea. Ou seja, na sua possibilidade de (des)cobrir o que está escondido, trazer à flor da pele. Quando esta visão se alia à criação artística fomenta-se um encontro transformador, capaz de fraturar ou ferir. Da performance "Secalharidade", João Fiadeiro e Fernanda Eugénio, sugerem que

O encontro é uma ferida. Uma ferida que, de uma maneira tão delicada quanto brutal, alarga o possível e o pensável, sinalizando outros mundos e outros modos para se viver juntos, ao mesmo tempo que subtrai passado e futuro com a sua emergência disruptiva.(EUGÉNIO \& FIADEIRO, 2012, p.1)

O encontro, tal como é sugerido, introduz a possibilidade de ampliação e de transformação. A ferida tornou-se o ponto de partida para este texto, uma ferida aberta que permite ver através da educação e da criação artística. Da experiência empírica, proveniente de uma prática coreográfica e pedagógica, levantaram-se questões sobre a interação entre estas esferas. A dança, a educação, a criação, o corpo, o professor, o aluno, o coreógrafo e o intérprete são superfícies que se cruzam e que se tornam um terreno fértil para reflexões e diálogos. Deste modo, importa a circunscrição destas questões de forma a perceber sobre que ferida estará presente neste texto. O trabalho coreográfico, em contextos educativos, aflorou a problemática e criou a necessidade de horizontalizar, colocando os processos educativos e coreográficos num mesmo plano. Ou seja, propor um diálogo comum entre o processo coreográfico e educativo, uma vez que na prática artística e educativa são sobrepostas as figuras do professor, aluno, coreógrafo e intérprete. Este facto cria um campo de problematização que conformará as linhas de força do texto. Deste modo, a discussão será exposta de acordo com a mesma transversalidade. Este é um aspeto específico de um trabalho de ligação entre conteúdos teóricos de duas áreas distintas: Educação e Arte.

\section{DANÇA A UM CORPO}

A dança, enquanto expressão artística, possui uma profunda capacidade de refletir sobre a realidade e a vivência sociocultural dos indivíduos (FAZENDA, 2012; LOUPPE, 2012; PASTORE \& PENTASSUGLIA, 2015). No caso específico da dança teatral, esta sublinha a relação obra-público e intérprete-coreógrafo na construção de uma performance definida "(...) por motivações artísticas e pressupostos estéticos determinados" (FAZENDA, 2012, p. 43). Este plano de relação, “(...) reenvianos para um quadro de criação em que o coreógrafo, bailarino e pensador, inventa não somente uma estética de espectáculo, mas um corpo, uma prática, uma teoria, uma linguagem motora. (...)" (LOUPPE, 2012, p. 46). Deste modo, a dança teatral permite a criação de um terreno fértil para o 
encontro de aspetos singulares como motivações artísticas, questionamento sobre a natureza da relação entre intérprete-coreógrafo e na reflexão sobre uma prática artística. Neste processo de estreitamento, ou seja, de pensar a dança como um grande campo de trabalho e, dentro desta, a dança teatral como um campo mais restrito, propõe-se a dança contemporânea como a unidade fundamental para pensar a criação. A escolha da dança contemporânea prende-se, por um lado, pelos aspetos empíricos no trabalho em torno desta técnica e, por outro lado, pelos aspetos específicos e únicos que contém para o desdobramento de questões em torno do corpo, da educação e da criação artística. Deste modo, a dança contemporânea torna-se um terreno fértil para pensar numa ética pedagógica. Contudo, antes de um mergulho na dança contemporânea nos seus aspetos artísticos e pedagógicos, será importante versar um pouco sobre o corpo que dança. Ou seja, sobre a entidade na qual estes fluxos operam e sobre a qual se articulam aprendizagens. Edificar um corpo através do qual todos os movimentos acontecem. E pensá-lo à luz do que o corpo pode, neste lugar de interseção entre a educação e a criação. O corpo, neste contexto, "(...) é agente, instrumento e objeto (...)" (FAZENDA, 2012, p. 61) sendo capaz de operar aprendizagens e criar sentido(s). Deste modo, o corpo desdobra-se em diferentes papeis e configurações. Coloca-se como um ponto fulcral no pensamento sobre a dança e o movimento na sua possibilidade de relação com o Mundo. O corpo que se pretende edificar, neste texto, é um corpo capaz de ser um agente de aprendizagem, um corpo ativo no processo de relação e afeção. A dimensão de instrumento e objeto, proposta por FAZENDA (2012), reposiciona-o e confere-Ihe uma tripla valência. Esta visão multimodal do corpo é fundamental quando se pensa nas suas infinitas possibilidades, e torna-se um aspeto importante na relação entre a educação e a criação. Se, por um lado, é um lugar de encontro com o Mundo é, por outro lado, um encontro com a sua singularidade. O corpo-agente opera sobre si e sobre os outros corpos tornando-se corpo-instrumento. O corpo-objeto sublinha a possibilidade de reposicionamento e, portanto, a ação externa sobre um corpo que se constrói. Desta forma, edifica-se um corpo como instância paradoxal. $\mathrm{O}$ corpo paradoxal é definido por GIL (2012) como um corpo-em-fluxo que "(...) pode ser desertado, esvaziado, roubado da sua alma e atravessado pelos fluxos mais exuberantes da vida. Um corpo humano porque pode devir (...)" (GIL, 2001, p. 68). Os corpos operam como superfícies de troca, superfícies que se reconfiguram e que se alteram continuamente. $\mathrm{O}$ corpo, na sua possibilidade de devir, tal como GIL (2001) propõe através de Deleuze, exalta uma linha de força importante na horizontalidade dos processos de criação e ensino-aprendizagem. Deste modo, o devir imanente ao corpo, não se prende com a imitação, nem com o confronto com um modelo externo ao qual deseja chegar, ou seja, "Becomings are not phenomena of imitation or assimilation, but of a double capture, of non-parallel evolution, of nuptials between two reigns." (DELEUZE \& PARNET, 2007, p. 2). Devir, em Deleuze, pertence à geografia, pertence ao movimento de entrada e de saída, contém orientações e direções. Ou seja, o movimento de 'tornar-se' ou a entrada no devir, implica uma saída da própria história. Propõe-se que, esta visão sobre o corpo, se articula com os aspetos enunciados sobre a dança contemporânea e, por conseguinte, terá de configurar uma ética e um posicionamento dos alunos e dos professores nos processos de criação e educação. Os corpos que participam ativamente nos processos de criação coreográfica, em contexto educativo, são "(...) bodies-in-the-making (...)" (MANNING, 2009, p.5). Importa evocar Manning uma vez que relaciona o corpo ao movimento, ou seja, 
propõe que os corpos são expressões dinâmicas de movimento e que a forma do movimento está contida no seu potencial incipiente. O início do corpo é o movimento. Um movimento inacabado, um movimento gerador de mais movimento, "(...) we move toward a notion of a becoming-body that is a sensing body in movement, a body that resists predefinition in terms of subjectivity or identity, a body that is involved in a reciprocal reaching-toward that in-gathers the world even as it worlds." (MANNING, 2009 , p. 6). O corpo torna-se no próprio movimento de devir, ou seja, o 'inacabamento' expressa-se através do movimento de se construir. Este campo abre uma fenda no próprio corpo, torno-o uma instância suscetível mudança transformando-o num lugar de aprendizagem. O corpo proposto por MANNING (2009) é plástico, é capaz de se mover na direção de uma noção sensível em movimento, um corpo que resiste à predefinição em termos de subjetividade ou identidade, "Thought here is not strictly of the mind but of the body-becoming." (MANNING, 2009, p. 5). Deste modo, o movimento não se opõe ao pensamento nem se encontra distanciado deste. O corpo permite, então, várias modalidades de pensamento. Desta forma, retomando GIL (2001), o corpo, através da dança, cria um “(...) plano de movimento onde o 'espírito e o corpo são um só'(...)" (p.95), onde há uma unificação dos sentidos e dos significados em ação porque "No movimento dançado o sentido torna-se ação." (p.95). Onde,

A dança traduz a massa do sentido incorporado ('embodied') e inarticulado ('embedded') em
trajectos intensivos, dissolvendo ao mesmo tempo no movimento o que surge como pura
ilustração cinestésica do verbal. Transforma as palavras e os gestos articulados pela linguagem em sentido ‘agido' pelo movimento. (GIL, 2001, p. 96)

Em suma, a dança, através do seu agente, o corpo, opera num conjunto de representações do próprio mundo. Onde a educação pelo corpo pode ampliar a noção de aprendizagem e projetá-la no sentido de um projeto humanista onde se interligam diferentes partes constitutivas do Ser Humano. Há, neste plano, "(...) um lugar de importância ao corpo, à sua aptidão para emitir e receber signos, para os inscrever sobre si mesmo, para traduzir uns nos outros" (GIL, 1997, p. 32). O corpo é, desde início, um veículo de pensamento sobre os signos, ou seja, sobre as formas e os conceitos.

Este é o corpo que se pretende evocar no contexto da dança contemporânea uma vez que, tal como será desenvolvido, este é o corpo mais justo. O corpo que serve o pensamento de uma contemporaneidade e que ajudará a pensar numa ética pedagógica transversal aos processos educativos e de criação coreográfica. Neste contexto, a dança contemporânea é caracterizada por diversos estilos e formas de trabalho, estes diferentes tipos de treino possuem um papel único capaz de desenvolver competências específicas (DIEHL \& LAMPERT, 2011). Deste modo, esta atua como um catalisador do processo de ensino-aprendizagem, na possibilidade de transformação do aluno e na sua relação com o Mundo. Os professores de dança contemporânea podem, deste modo, formar uma rede híbrida que une formas de dança e técnicas de trabalho corporal, juntamente com métodos de apresentação e várias formas de ensino. Ao mesmo tempo, o método contribui para o estilo, onde a forma de trabalhar informa qualquer prática artística individual. Partindo deste ponto de vista, propõe-se uma reflexão sobre a multimodalidade e a capacidade de absorção que a dança contemporânea possui. Através desta técnica de dança, os professores são convocados a partilhar muitas experiências 
e habilidades nas suas abordagens de ensino. O papel do professor de dança contemporânea está de acordo com a sua singularidade uma vez que "Any given teacher's personal preferences, experiences, or encounters with other techniques and teaching methods inevitably influences and even transforms that teacher's body of information." (DIEHL \& LAMPERT, 2011, p. 12). A informação contida no corpo do professor permite a possibilidade de abertura de um trabalho técnico com visões pessoais provindas da prática artística, pedagógica ou filosófica, capaz de aumentar o espetro do treino do corpo nas suas várias vertentes. Este é um aspeto fundamental, uma vez que é necessária uma prática pedagógica física e artística globalizante. SÖÖT \& VISKUS (2014) propõem uma visão holística do professor de dança como forma de antever as tendências de desenvolvimento e os desafios da pedagogia no contexto da dança contemporânea. Onde

\footnotetext{
Everything is in intercommunication; it is a conscious activity of compiling learner's world view. Holistic approach of contemporary fragmented world should be involved with drawing the whole together - uniting the body and the mind, the teaching and the identity, the curriculum and the community, so that they could address the human as a whole. (SÖÖT \& VISKUS, 2014, p. 291)
}

Os autores defendem que o professor deve ter em consideração que o todo é composto de partes valiosas independentes e deve ser capaz de identificar e fazer uso construtivo dessa sinergia. Perspetiva na qual, o professor, assume o papel de mediador entre o estudante e o mundo. Deste modo, o professor, que ensina através do seu corpo, convoca a suas experiências para criar novas experiências nos alunos. O corpo, instância partilhada pelo aluno e pelo professor, transforma-se numa lente de aprendizagens. Isto é, o corpo, na sua instância paradoxal, permite que tanto o professor como o aluno partilhem o processo de mudança através do seu potencial de devir imanente. Desta forma, a dança contemporânea coloca-se no espaço de interseção de vários planos, plano alunoprofessor, plano aprender-ensinar, plano individual-coletivo. Onde, das diversas experiências do professor e do aluno, emerge uma nova instância de criação de aprendizagens. Esta é uma das linhas de força desta reflexão, uma vez que é necessário pensar na relação professor-aluno e nas suas possibilidades. E, neste lugar de relação, pensar nesta ética pedagógica no contexto da criação onde os corpos assumem um papel preponderante no movimento dos conceitos.

\section{A CHAVE E A FENDA}

Como forma de continuar o pensamento sobre a educação, propõe-se um 'voltar à escola'. Ou seja, um pensamento sobre a Escola na edificação de uma educação que abarque o corpo e o movimento propostos anteriormente. Assim, importa propor uma geografia de agentes, um posicionamento que mergulha no processo de relação. Pensar o lugar do professor e pensar o lugar do aluno, ajudará a criar uma nova linha de força que sustenta a visão e uma criação comum. Para este pensamento, serão colocados em relação alguns aspetos pedagógicos enunciados por Bruner e Vygotsky. Uma vez que permitem discutir sobre a geografia dos agentes no processo de ensino aprendizagem. 
Bruner aproxima a Vida da Cultura afirmando que esta possuiu um 'estojo de ferramentas comuns' (BRUNER, 2008) que permite que a mente crie significados. Neste contexto a Cultura é vista como construtivista, anti essencialista e pluralista (MATTINGLY \& THROOP, 2010). Neste sentido, BRUNER (1996), afirma que a Cultura é 'superorgânica' através da apropriação da expressão de KROEBER (1955). Importa que se contextualize, brevemente, esta noção uma vez que permite ver a Cultura como algo maior do que cada indivíduo. Ou seja, a Cultura tem uma existência fora do indivíduo e sugere padrões coletivos de comportamento. Neste contexto, importa entender a Cultura como uma esfera maior que o indivíduo, mas que afeta diretamente o comportamento individual. Onde, na sua expressão individual, Bruner defende que a Cultura possui uma capacidade de moldar a mente dos indivíduos através da 'formação de significados'. Esta, por seu turno, envolve

(...) encontros situacionais com o mundo nos seus contextos culturais adequados, para saber "a que se referem". Embora os significados estejam "na mente", têm origem e significação dentro da cultura na qual foram criadas. (BRUNER, 1996, p. 20)

A visão da mente proposta por Bruner, constitui e é constituída pela Cultura, estabelecendo uma psicologia interessada na ação e no seu caráter situacional, onde o processo de produção de significados é realizado com o auxílio dos sistemas simbólicos da Cultura (CORREIA, 2003). A Cultura pode, neste contexto, ser definida como "(...) um conjunto de elementos simbólicos da vida social, ou seja, um conjunto de representações, valores morais e ideais que institui e organiza a sociedade" (CATANI, NOGUEIRA, HEY \& MEDEIROS, 2017, p.135). Esta noção de Cultura baseia-se na visão de Bourdieu, e permite estabelecer uma ponte com Bruner e o seu 'estojo de ferramentas comuns'. Uma vez que se estabelece uma relação entre as estruturas psicológicas e o Mundo, através dos sistemas simbólicos, e da 'situacionalidade' na formação dos significados. No contexto escolar, o 'capital cultural' , descrito por BOURDIEU (1999), torna-se um fator preponderante no desenvolvimento humano e sublinha o papel constituinte da Cultura no sucesso escolar do aluno. Deste modo, há uma relação estreita entre o nível cultural global da comunidade ou família e o grau de sucesso do aluno na escola (BOURDIEU, 1999). Em suma, existe uma relação estreita entre a Cultura e o desenvolvimento das estruturas psicológicas. Esta relação dilata-se, deste modo, para o meio e para a vivência em sociedade. O que levanta um novo campo de pensamento, que se prende com a relação entre a Escola e a Comunidade. VIEIRA (2013), munindo-se das palavras de Américo Peres, sublinha que a sociedade e a Escola são, progressivamente, complexas e multiculturais. Havendo, portanto, a necessidade de repensar o papel das instituições públicas de ensino na sua capacidade de ensinar a aprender a viver em comunidade. A educação é articulada com o desenvolvimento comunitário e na construção de pontes com a sociedade, uma vez que

(...) sem educação não há cidadão e a cidadania global não se constrói discriminando os grupos sociais subalternizados, violando os direitos políticos e civis, económicos e sociais, ambientais, todos eles interdependentes e a necessitarem de políticas que os legitimem (...) (PERES, 2002, p.4 citado por VIEIRA, 2013, p.38) 
Desta forma, a escola, enquanto espaço social e educativo, consiste num microcosmo da sociedade e deve ser encarada como um “(...) processo de mediação entre sujeitos, contextos e saberes (...)" (VIEIRA, 2013, p.38). A educação, recorrendo à imagem do início deste texto, enquanto ação de 'trazer para o exterior' imprime, no professor, um papel de mediador de aprendizagens. Ou seja, um elemento que faz a ponte entre as várias instâncias que convivem na escola: Cultura, sociedade, educação. Assim, “(...) o professor terá de pensar a educação também além da sala de aula porque é daí, das famílias e das comunidades, que vêm os alunos e suas identidades pessoais (... ) que se encontram no espaço escolar." (VIEIRA, 2013, p.38).

Voltando à noção de geografia, foi possível, até agora, reposicionar os agentes sobre os quais importa pensar este texto. Um indivíduo, independentemente da sua posição, é constituído por Cultura e é, através desta, que se completa psicologicamente. Este capital cultural é de extrema importância e terá de ser tomado em conta quando aplicado à Escola. O professor e o aluno posicionam-se lado a lado, entre a escola, que é o mundo, e a aprendizagem, que é cultural. Esta é uma das linhas de força que Bruner defende. BRUNER (1996), em oposição à visão computacionalista², considera que a mente humana pode ser abordada através do culturalismo, ou seja, que esta não pode existir separada da cultura.

\footnotetext{
É que a evolução da mente hominídea está ligada ao desenvolvimento do modo de viver em que a 'realidade' é representada por um simbolismo partilhado pelos membros de uma comunidade cultural (...) (BRUNER, 1996, p.19).
}

Ou seja, a Cultura tem a capacidade de moldar a mente dos indivíduos onde a sua expressão individual "(...) inscreve-se na formação de significado, atribuindo significados às coisas segundo diferentes arranjos em ocasiões particulares (...)" (BRUNER, 1996, p.20). Conclui-se, assim, que através da perspetiva de VIEIRA (2013) a Escola assume-se multicultural e como um microcosmo do Mundo. BRUNER (1996), por seu turno, sublinha a Cultura no seu papel preponderante na formação da mente humana através da produção de significados. Deste modo, através do 'estojo de ferramentas' , é possível retirar uma chave que dá a ver o Mundo ao sujeito. E é, neste interstício, nesta fenda, que o professor se poderá colocar sendo um intermediário no processo de formação e de relação entre a fenda, o sujeito e o mundo. Desenhou-se, até agora, um mapa que permite ter uma visão expandida do professor, do aluno e da Escola, independentemente do contexto. Contudo, é necessário reduzir o campo, ou seja, focar a atenção sobre a relação entre o professor e o aluno. Uma vez que é, através desta interação, que se operam aprendizagens e é, através desta, que se desenvolve um processo de criação.

\section{O ESPELHO E O ANDAIME}

\footnotetext{
2 “(...) a expressão 'visão computacionalista', (...) [é baseada em] dois modelos deste género: um baseado na ideia da mente enquanto aparato de recursos computacionais que operam em paralelo e sem vantagem de um sistema processador central, o outro, na ideia de um dispositivo processador central que controla a ordem sequencial das operações computacionais que devem ser executadas para conseguir soluções a problemas particulares." (BRUNER, 1996, p. 18)
} 
A figura do professor é, neste contexto, a de um intermediário no processo de ensinoaprendizagem, ou, um catalisador da relação entre a realidade e a aprendizagem. Porque "Quando alguém com autoridade de professor descreve o mundo e nele não nos inserimos, há um momento de desequilíbrio psíquico, como se olhássemos para um espelho e nada víssemos (...)” (BRUNER, 2008, p. 49). De facto, a mediação entre mente e cultura deve ser preconizada pela educação onde, o já referido 'estojo de ferramentas comuns' ou cultura, será capaz de facultar instrumentos para poderem ser captados pelos indivíduos. A Escola permite, desta forma, uma (re)significação da realidade captada através dos “(...)signos sociais, os quais são negociados ou compartilhados por meio deste processo. E pode-se inferir neste item que a escola é uma comunidade na qual os indivíduos negociam os seus significados." (RABATINI, 2010, p. 29). Sublinha-se o termo 'negociação', sugerido por Rabatini, uma vez que introduz uma outra camada no processo de aprendizagem. Ou seja, a possibilidade de fomentar uma pedagogia não é linear e que se constrói pela interação entre professoraluno de uma forma recíproca através do processo de significação da realidade. Este aspeto é fundamental para entender o processo de criação coreográfica na perspetiva colaborativa que será desenvolvido adiante. Bruner, por seu turno, enfatizou que os professores devem ensinar os alunos a pensar e descobrir a realidade da qual fazem parte. O desequilíbrio psíquico, referido anteriormente, impede a formação das suas próprias experiências de conhecimento e de significação. Com a 'teoria da aprendizagem por descoberta', Bruner, afirma que o professor deverá incitar os alunos a aprender através das suas estruturas de captação da realidade. Ou seja, desenvolver conhecimentos através de uma relação de espelhamento da realidade nas suas estruturas psicológicas, isto é, convocando o capital cultural do aluno no processo de ensino-aprendizagem (BRUNER, 2011). Assim, o ambiente de ensino eficaz deve estimular a curiosidade dos alunos e manter os seus interesses, bem como orientar os alunos para a exploração e divergência nas direções corretas. Neste sentido LIAO (2012) , apoiando-se em Bruner, reforça a ideia de que

(...) every subject contains basic principles, concepts, and structures, as long as the teacher can present the structure of curriculum, he/she then can help students understand principle of such subject and percept the new structure in order to achieve the purpose of learning transferring. (p.178)

Neste contexto, no processo de ensino-aprendizagem, o professor assume um papel de proporcionar uma estrutura que ajuda os alunos a aprender. Onde, cada aluno, é visto como um indivíduo que já possui um conjunto de estruturas e de informação na sua perceção da realidade. $\mathrm{O}$ professor é, desta forma, um 'gestor' do capital cultural dos alunos e deverá encontrar uma forma de o mobilizar. Assim, o professor, enquanto mediador desta informação, dirige-a para áreas de interesse que despertam a curiosidade através de um processo de negociação com o aluno. Este processo de estruturação e de acompanhamento é descrito, por Bruner, como scaffolding (andaime). A este respeito GRANOTT (2005) citando WOOD, BRUNER \& ROSS (1976) define 'andaime' como “(...) a process that enables a child or a novice to solve a problem, carry out a task, or achieve a goal which would be beyond his unassisted efforts' (...)" (p.140). Esta visão do professor, como tutor, foi profundamente 
influenciada pela zona de desenvolvimento proximal (ZDP) proposta por Vygotsky (BRUNER, 2009). Este definiu ZDP como

(...) the distance between the actual developmental level as determined by independent problem solving and the level of potential development as determined through problem solving under adult guidance or in collaboration with more capable peers (...) (VYGOTSKY, 1978 citado por GRANOTT, 2005, p.141).

GRANOTT (2005) refere que o conceito de 'andaime', inicialmente, foi aplicado à interação criança-adulto ou aluno-professor, focando-se numa relação unilateral. Esta visão, atualmente, foi ampliada, considerando-se que está demasiado centrada no professor e de como este vê o comportamento do aluno. Para colmatar esta unilateralidade e aumentar a responsabilidade mútua ou partilhada, o 'andaime' foi ampliado para outras interações, nomeadamente, aluno-aluno ou até alunocomputador. Desta forma, a criação de ZDP, não depende somente dos agentes que promovem a relação, mas da qualidade da própria relação.

Nesta secção do texto, sublinhou-se a importância do espelho e do andaime na construção de aprendizagens. Estes são instrumentos-metáforas que permitem pensar o processo de aprendizagem, criando linhas de força importantes na relações professor-aluno. O objetivo foi extrair, brevemente, conceitos importantes para pensar essa relação. O espelho, por sua vez, sugere uma visão sobre a realidade e de confronto consigo mesmo. Estabelecendo uma ponte entre o exterior e o interior, o espelho pode ser uma janela, um vidro, uma superfície que reflete e se deixa atravessar. Enquanto que o andaime remete para a ideia de estrutura, de cuidado, de envolvência. $\mathrm{O}$ andaime serve o propósito de apoiar a construção, neste caso, o sentido da construção é invertido. Isto é, não é o construtor que ergue as paredes do lado de fora, mas as paredes erguem-se pelo lado de dentro. São paredes construídas a quatro mãos, suportadas pela estrutura que se reconfigura permanentemente. Foi possível, assim, balizar o campo de discussão no processo de ensino-aprendizagem e estabelecer um plano horizontal e comum à educação e à criação artística. Optou-se, deste modo, pelo afastamento da dança para que se pudesse pensar na relação entre os agentes professor e aluno. De forma a estabelecer conceitos-base importantes para pensar a criação artística nos contextos educativos.

\section{A CRIAÇÃO NA COLABORAÇÃO}

Depois de pensar a dança contemporânea como lugar de pensamento sobre o mundo e de como o professor e o aluno se poderão posicionar relativamente a essa realidade. Importa, a esta altura, convocar a criação coreográfica de modo a triangular os três núcleos fundamentais deste texto: dança, educação e criação. A criação coreográfica encerra uma multiplicidade de métodos e processos de construção uma vez que "(...) reconfiguram o corpo, o movimento, os formatos de apresentação, a definição de coreógrafo e intérprete, e as relações entre os diversos elementos constitutivos da obra coreográfica." (XAVIER, 2017, p. 28). Desta multiplicidade, insurge-se a singularidade das propostas coreográficas através da composição coreográfica, ou seja, através da possibilidade de “(...) manipular e organizar os diversos elementos da coreografia - movimento, espaço, luz, cenários e elementos cénicos, música e som, entre outros." (MARQUES \& XAVIER, 2013, p. 54). A coreografia remete para 
o processo singular através do qual um artista não só organiza e cria movimento, mas também a forma como cria significados através deste. A coreografia é, deste modo, um procedimento de criação singular e, ao mesmo tempo, plural. Onde, os processos de criação coreográfica contribuem para a associação de princípios conceptuais na sua relação com o trabalho físico, ou seja, sustentam um agenciamento físico através de um plano ideacional. Esta viagem é capaz de induzir, no aluno, um desenvolvimento das suas componentes cognitivas e físicas contribuindo para que este seja capaz de ‘ abrir' o corpo ao mundo e deixar que este mundo o afete. Autores como SMITH-AUTARD (2010), LAVENDER (2006) e DAVENPORT (2011) sublinham os aspetos da improvisação, levantamento e escolha de material coreográfico, relação professor-coreógrafo e aluno-intérprete como transversais nos processos de criação e composição coreográfica. A este ponto, importa convocar o mapeamento desenhado anteriormente na relação entre professor-aluno e Cultura-Escola. A dança, tal como já foi referido, permite-se ser um lugar de relação e de encontro, de geração de uma fenda na relação entre o corpo e o mundo. A cultura, como instrumento constitutivo do indivíduo, permite que este (re)signifique a realidade e que se deixe afetar por esta. Sugere-se, assim, o processo de criação coreográfica como lugar com potencial de fomentar aspetos singulares no indivíduo de forma a que este reconheça as suas próprias estruturas e seja capaz de, através delas, entender o objeto artístico. O professor poderá, neste contexto, promover a circulação de conhecimento e de exploração criativa dentro da estrutura cognitiva do aluno. Através da responsabilidade partilhada e da pedagogia da descoberta, é possível (re)pensar os processos de criação coreográfica em contexto educativo aproximando-os da visão da educação que se circunscreveu anteriormente. Embora não seja possível uma transcrição direta, das premissas propostas por Bruner e Vygotsky, é possível estabelecer uma rede que sustenta a reflexão que este texto pretende efetuar. Ou seja, no estabelecimento de um plano transversal ao processo de ensino-aprendizagem e de criação coreográfica. Esta rede, sustentada através de um corpo paradoxal e de uma relação horizontal entre os agentes professor-aluno, permite repensar uma ética de relação independentemente do contexto.

Pode afirmar-se, desta forma, que o processo criativo, tal como o processo de ensinoaprendizagem, implica uma interação entre professor-aluno ou coreógrafo/diretor e intérprete/bailarino. Importa, antes de desenvolver esta relação, proceder à desambiguação do binómio intérprete/bailarino para que se possa estabelecer o posicionamento face ao papel dos agentes da criação. Muito embora possam parecer sinónimos estas palavras possuem significados diferentes e podem ser usadas em contextos coreográficos distintos. A este nível, FAZENDA (2012), refere, a propósito do uso das palavras "coreógrafo" ou "direção artística" ou "direção e coreografia", que o uso da palavra "intérprete" suplanta a palavra "bailarino". Onde atribuiu, ao agente que dança, o intérprete, um papel fundamental também no processo criativo uma vez que é entendido como um sujeito capaz de, através das suas características e singularidade, contribuir ativamente no processo criativo (FAZENDA, 2012). Colocando num mesmo plano os conceitos de processo coreográfico, processo pedagógico, operações do ato de criar e contexto coreográfico. É possível inferir que o modo de 'fazer dança', ou seja, criação de uma obra coreográfica implica a relação entre as figuras de coreógrafo e intérprete e que esta relação possui uma miríade de formas. A este respeito, BUTTERWORTH (2009) propõe um DidaticDemocratic framework model (Modelo Didático-Democrático) para o ensino de coreografia. Este 
modelo apresenta uma abordagem aos conceitos de criação em dança e devising ${ }^{3}$ num contínuo de cinco abordagens genéricas diferentes num processo coreográfico. O modelo assume que o intérprete possui algum conhecimento e domínio do conceito de coreografia. Onde o coreógrafo assume diferentes papeis que variam consoante a sua relação com os intérpretes situada num espetro desde o didático (ensinar por imitação) ao democrático (abordagem colaborativa).

Within the didatic-democratic model, a dance artist-practitioner is defined as an experienced, multi-skilled individual: a dancer who may also choreograph and teach, a teacher who may also choreograph and dance or a choreographer who may also dance and teach. (BUTTERWORTH, 2009, p.178)

A autora defende ainda que este modelo permite: (1) identificar preferências pessoais; (2) reconhecer as necessidades específicas dos agentes na aplicação de competências coreográficas; (3) conferir um conhecimento mais profundo da influência de fatores contextuais no processo coreográfico. Estes processos não seguem uma linearidade progressiva apenas propõem uma reflexão do papel dos agentes no processo coreográfico no que respeita às interações, metodologias de liderança e abordagens coreográficas. Aqui são explicitados níveis de saber diferentes imprimindo, deste modo, métodos de ensino, interação social e aprendizagens particulares. Do modelo Didático-Democrático proposto por BUTTERWORTH (2009), constata-se que existem processos de devising que permitem a partilha de papeis e de responsabilidade pelos métodos de colaboração ou decisão conjunta. Ou seja, devem ser assentes em premissas onde "(...) artists might develop trust and respect, come to common understanding and clarify intentions, roles and agendas." (BUTTERWORTH, 2009, p. 189). Citando SCHIRLE (2005, p.92), Butterworth reforça que "In the crucible of devising, each group must strike its own balance between the productive engagement of artistic egos and the genorosity of the collaborative spirit." (BUTTERWORTH, 2009, p. 189). Durante o processo de devising há sempre o risco de uma sobreposição do compromisso entre ideias artísticas e estéticas e a visão pessoal. Contudo existem muitos benefícios desta partilha, para

(...) ensemble of dancer creators engaged in creating original work, the compounding ideas and energy provide personal knowledge of intent and context for all members. The developing work cannot be mindless; it demands critical thinking. (BUTTERWORTH, 2009, p.189).

O processo de devising e a criação coreográfica democrática, ou seja, partilhada, ecoa nos aspetos discutidos anteriormente sobre a horizontalidade da relação professor-aluno. Ou, neste caso, coreógrafo-intérprete. Através deste modelo é possivel pensar na migração dos papeis dos agentes que desenvolvem o processo criativo. Embora Butterworth não se debruce, especificamente, sobre a ZDP ou o conceito de andaime, é possível convocar esta visão para o contexto da criação coreográfica

\footnotetext{
${ }^{3}$ Neste texto será utilizada a designação original da palavra Devising, a autora refere que "Dance Devising involves dialectic between the acts of making and doing, or creating and performing, of being an artist and/or interpreter. By implication the notion of shared roles and responsibilities is important. Perhaps by collaborative methods, or by collective decision-making processes, the creation of dance as art is attempted by more than one artist." (BUTTERWORTH, 2004, p. 53)
} 
em contexto educativo. Ou seja, o aluno poderá assumir o papel de coreógrafo e de intérprete num mesmo processo criativo. Desta forma, partilha a responsabilidade do processo com os outros alunos e com o professor numa multiplicidade de relações aluno-aluno, aluno-professor. Onde ambas são geradoras de aprendizagens através da ZDP que se cria. O professor assume, por seu turno, o mesmo papel de mediador no processo criativo de modo a promover, simultaneamente, uma reflexão estética (inerente a uma obra artística) e uma reflexão pedagógica.

Os lugares de interseção são, muitas vezes, lugares frágeis. Isto é, lugares onde se criam sobreposições que abrem campos de problematização. Neste caso específico, o lugar da criação em contexto educativo, permite expor os aspetos relacionais e de partilha de poder, com os aspetos estéticos e criativos inerentes a uma obra coreográfica. Se, por um lado, um objeto artístico é, por si mesmo, uma forma de estabelecer uma ligação com o mundo, por outro, no contexto educativo, existe uma ampliação do mesmo para outras questões que se prendem com a colaboração. Desta forma, importa, discutir os aspetos éticos e pedagógicos inerentes a uma prática artística que contém, num mesmo processo, uma dimensão singular e uma dimensão partilhada.

\section{UMA ÉTICA DE CRIAÇÃO}

No contexto do ensino artístico da dança é uma prática comum os coreógrafos trabalharem num ambiente educacional ou mesmo os professores trabalharem como corógrafos, criando um agente híbrido como professor-coreógrafo. Estes, por seu turno, através dos estudantes de dança realizam o seu trabalho artístico inserido no campo da composição e criação coreográfica. Estes professorescoreógrafos são, intrinsecamente, um ponto convergente de questões artísticas e pedagógicas. A dinâmica inerente da relação professor-aluno gera questões éticas que podem afetar a coreografia e a experiência de aprendizagem do aluno. HAINES (2006) levanta algumas questões que se tornam pertinentes após a viagem proposta neste texto: (1) Em que ponto decisões coreográficas imprimem metas para uma pedagogia centrada no aluno? (2) Como pode o modelo tradicional de coreógrafo no centro do processo cruzar com os objetivos curriculares? A autora coloca, ao mesmo nível, a possibilidade de um processo criativo servir um propósito pedagógico sem que perca as suas características fundamentais. É referido que, como artistas e educadores, é alocado ao professor a responsabilidade de manutenção da qualidade de ensino e de um processo criativo significativo. Assim, devem ensinar, conduzir e modelar um processo coreográfico que permita aos alunos envolver-se criticamente com a resolução de problemas e tomada de decisões. Sugere-se alcançar uma pedagogia ética, centrada no aluno mesmo quando é a visão abrangente do professor-coreógrafo que estabelece um padrão artístico e aglutinador.

What I want to be doing as an educator, however, is to use strategies that ensure a respect for students of all learning styles and backgrounds. I want to employ pedagogical methods that will support students in their development as critical thinkers and self-directed learners. (HAINES, 2006, p. 15) 
Assim, cabe ao professor-coreógrafo fornecer um nível de desafio aos alunos-intérpretes no sentido de desenvolver um trabalho coreográfico artisticamente relevante, que possa fomentar o compromisso próprio com um compromisso honesto e reflexivo sobre a pedagogia. Este é um ponto convergente que a autora não refere, mas que se sugere como transversal entre a pedagogia da descoberta proposta por Bruner e a ZDP de Vygotsky. Ou seja, a possibilidade de o professorcoreógrafo não ser o centro gerador de materiais, mas antes um facilitador, incitador, aglutinador capaz de fornecer e estabelecer um processo criativo democrático baseado no processo de devising proposto por Butteroworth. Deste modo, devem ser exploradas a natureza da colaboração, numa ampla gama de práticas. De facto, o conceito de colaboração, num processo criativo é, neste contexto, a sua pedra basilar e traz benefícios para a formação do aluno-intérprete. Ao abrir a possibilidade de entrada neste mundo sensível, os alunos entendem como pode um processo criativo de criação em dança conferir ferramentas que desenvolvam a sensibilidade e a reflexão sobre uma prática física, artística e cultural. Esta posição revela um potencial pedagógico enorme e induzem uma pedagogia transformativa descrita por HAINES (2006).

I am undermining student-centered pedagogical values and negating constructivist theories of education that define learning as the knowledge and meaning 'constructed' by students processing new information along with their own life experiences. (HAINES, 2006, p.15).

Seguindo os princípios da educação transformadora esta vê, na dança e no processo colaborativo, uma oportunidade de oferecer uma alternativa educacional para o ensino tradicional. " Collaborative approaches to choreography appear to evade the authoritarianism that is seen as governing the traditional choreographic process and offer students valuable experience in decision making and negotiation." (HAINES, 2006, p.15). Pensando na questão tradicional, importa colocar a figura de professor como agente que se questiona, que faz com que o tradicional não se acomode apenas pela longevidade de uma prática. Desta forma, é possível (re)pensar a figura de poder e de autoridade do professor-coreógrafo. FARRER (2014) incita a este pensamento uma vez que essa perceção tradicional e bem enraizada, muitas vezes, faz com que o coreógrafo apareça como o único sujeito criativo no processo de criação onde, desta visão, "The everyday acts undertaken by dancers seem to be considered more as responses to a choreographer's creativity, rather than valued as creativity in their own right." (p.95). Contudo, tal como demonstra, esta não é a realidade das companhias de dança ou dos projetos de criação. Dentro do atual clima da dança contemporânea, há uma infinidade de abordagens e de métodos e processos de criação, o que implica uma amplitude, cada vez maior, dos papéis dos agentes da criação. Onde existe uma maior sobreposição da relação entre intérprete e coreógrafo, convidando o público a reconsiderar suas perceções de criatividade (FARRER, 2014).

\section{UM FIM QUE PODERIA SER UM INÍCIO}


Através deste texto pretendeu-se estabelecer um diálogo entre uma atitude pedagógica e o processo de criação coreográfica. Desta malha que cruza aspetos gerais e particulares das áreas em estudo, a Educação e a Arte, a horizontalidade é um dos aspetos importantes na reflexão. Neste plano, é possível refletir sobre questões de posicionamento, ou geografia, um posicionamento que extravasa, muitas vezes, os aspetos da Educação ou da Arte. Este atrai um aglomerado de forças em torno da colaboração, democracia e diálogo. A educação artística, através do processo de criação, poderá, desta forma, contribuir para o desenvolvimento de múltiplas capacidades dos seus agentes e permitir, por sua vez, uma (com)posição política e estética na Escola. Este é um posicionamento, perante a criação e a educação, que encoraja a assunção de riscos e promove uma pedagogia que não é totalmente controlada por resultados de aprendizagem específicos. Há, nesta visão, a possibilidade de uma não linearidade dos métodos e processos de criação uma vez que são, verdadeiramente, influenciados por vários fatores. O professor-coreógrafo deixa de ser a figura dominante e coloca-se como espetador de um espetáculo partilhado. Isto não significa que se desresponsabilize no processo, mas está presente como figura de suporte no desenvolvimento do processo. No contexto educativo, contrariamente a um contexto artístico 'comum', a forma de abordagem coreográfica do professorcoreógrafo é tão importante como a sua atitude pedagógica. São planos que não se anulam, mas que se encontram e, através da sua união, o professor-coreógrafo poderá encontrar novos lugares. A educação artística é, neste contexto, a cicatrização da ferida que se abre quando se aproxima a pedagogia da criação coreográfica. Desta forma, importa pensar os processos e as práticas de criação coreográfica contemporânea através do espelho pedagógico. A possibilidade de experimentação e de improvisação, tão importantes na esfera da criação, tornam-se ferramentas pedagógicas com um grande potencial. Assim, o professor-coreógrafo, convoca uma maior responsabilidade no alunointérprete na criação do material coreográfico. Desta forma, a substância imaterial da dança é construída pela negociação entre o suporte do professor-coreógrafo e o capital cultural do alunointérprete. Esta constitui-se como uma unidade fundamental de um processo criativo pensado sob a perspetiva socio-construtivista da criação na Escola. A escolha, o refinamento e o desenvolvimento do material coreográfico, nesta perspetiva, são oportunidades de encontro do sujeito com o Mundo e de uma (re)significação do objeto artístico. Uma vez que o objeto artístico não é algo exterior ao sujeito, mas contém um reflexo deste. O espelhamento permite uma ampliação da relação dos agentes com o objeto e é, na multiplicidade das ligações, que se afloram valores educativos preciosos. Estes não se prendem unicamente com aspetos físicos ou de mestria técnica, mas com visões mais profundas no plano de relação sujeito-Mundo. Pretende-se, deste modo, criar aprendizagens significativas que estabelecem uma ponte entre modos-de-viver e de percecionar o mundo. Olhar para um espelho e nada ver cria um distanciamento irreparável no processo educativo e é, neste lugar de 'se-dar-a-ver', que importa pensar a criação e a educação.

A criação é, tal como o corpo, é um lugar paradoxal, na medida em que é capaz de se (re)configurar de acordo com os variados métodos e processos coreográficos. Assume várias formas e está intrinsecamente relacionada com a autoria, ou seja, com a singularidade. Desta forma, é na partilha e na diluição da visão singular que se poderá desenvolver uma ética de criação educativa. Desta forma, os conceitos de processo criativo, composição coreográfica, métodos e processos de 
criação, educação-criação, professor-mediador e espetro didático-democrático são pilares que sustentam todo este pensamento. E que, por seu turno, impõem uma reflexão ética inerente aos processos artísticos e educativos. Em suma, partindo de um conjunto de motivações de ordem empírica, pretendeu-se refletir sobre a prática artística e pedagógica. Esta reflexão propõe aspetos importantes sobre a operacionalização de um processo de criação em contexto educativo. Não se pretende sugerir um modelo ou um modo de operar, mas sim, linhas de pensamento. Estas linhas não anulam qualquer tipo de singularidade artística ou pedagógica, mas aproximam aspetos basilares da educação contemporânea e de uma prática artística de criação e composição em dança. Cabe ao professor ou coreógrafo pensar a sua realidade e contexto, e que esteja atento a estas questões. Há, neste texto, um incentivo na busca de uma 'voz' própria e que, através desta, se possa (re)pensar uma prática artística-pedagógica.

\section{REFERÊNCIAS}

1. ATKINSON, D. (2008). Pedagogy of the Event. University of London, 1-10. Retrieved from http://www.kettlesyard.co.uk/exhibitions/mi/papers/onn_atkinson.pdf

2. BOURDIEU, P. (1999). Escritos de educação. Editora Vozes. Retrieved from https://books.google.pt/books?id=GVCcQwAACAAJ

3. BRUNER, J. (1996). Cultura da educação. Lisboa: Edições 70.

4. BRUNER, J. (2008). Actos de significado (2a). Lisboa: Edições 70.

5. BRUNER, J. (2009). Actual Minds, Possible Worlds. Harvard University Press. Retrieved from https://books.google.pt/books?id=YNuBf6W2rt0C

6. BRUNER, J. (2011). O processo de educação (1a). Lisboa: Edições 70.

7. BUTTERWORTH, J. (2004). Teaching choreography in higher education: a process continuum model. Research in Dance Education, 5(1), 45-67. https://doi.org/10.1080/1464789042000190870

8. BUTTERWORTH, J. (2009). Too many cooks? A framework for dance making and devising. In J. Butterworth \& L. Wildschut (Eds.), Contemporary Choreography: A Critical Reader (pp. 177-194). London: Routledge.

9. CATANI, A. , NOGUeIRA, A., HEY, P., \& MEDEIROS, C. (2017). Vocabulário Bourdieu. Autêntica editora It. Retrieved from https://books.google.pt/books?id=uSXTswEACAAJ 

de significados. Estudos de Psicologia (Natal), 8(3), 505-513. https://doi.org/10.1590/S1413294X2003000300018

11. DAVENPORT, D. (2011). Building a Dance Composition. Journal of Dance Education, 6, 25-32. https://doi.org/http://www.tandfonline.com/doi/abs/10.1080/15290824.2006.10387309

12. DELEUZE, G., \& PARNET, C. (2007). Dialogues II. New York: Columbia University Press. Retrieved from https://books.google.pt/books?id=iqKGldo7A2gC

13. DIEHL, I., \& LAMPERT, F. (Eds.). (2011). Dance Techniques 2010 Tanzplan Germany. Henschel.

14. EUGÉNIO, F., \& FIADEIRO, J. (2012). O encontro é uma ferida. In Secalharidade. Lisboa: Culturgest.

15. FARRER, R. (2014). The creative dancer. Research in Dance Education, 15, 95-104. https://doi.org/10.1080/14647893.2013.786035

16. FAZENDA, M. (2012). Dança Teatral: Ideias, Experiências, Ações. Lisboa: Edições Colibri.

17. GIL, J. (1997). Metamorfoses do corpo (2a). Lisboa: Relógio d'água editores.

18. GIL, J. (2001). Movimento total - o corpo e a dança. Lisboa: Relógio d'água editores.

19. GRANOTT, N. (2005). Scaffolding dynamically toward change: previous and new perspectives. New Ideas in Psychology, 23(3), 140-151. https://doi.org/10.1016/j.newideapsych.2006.07.002

20. HAINES, S. (2006). Ethics and Aesthetics - the artist-educator and choreographic process. Journal Od Dance Education, 6, 14-18.

21. KROEBER, A. L. (1955). The Superorganic. Retrieved from https://books.google.pt/books?id=yQjTAAAAMAAJ

22. LAVENDER, L. (2006). Creative Process Mentoring: Teaching the "Making" in Dance-Making. Journal of Dance Education, 6(1), 6-13. https://doi.org/10.1080/15290824.2006.10387306

23. LIAO, S. (2012). The application of Piaget and Bruner's cognitive-developmental theory in children' s dance teaching. Journal of Arts Education, 164-197.

24. LOUPPE, L. (2012). Poética de dança contemporânea (1a). Lisboa: Orfeu Negro. 
MANNING, E. (2009). Relationscapes. Cambridge: MIT Press. https://doi.org/10.7551/mitpress/9780262134903.001.0001

26. MARQUES, A., \& XAVIER, M. (2013). Criatividade Em Danca. Revista Portuguesa de Educação Artística, 47-59.

27. MATTINGLY, C., \& THROOP, J. (2010). Bruner's Search for Meaning: A Conversation between Psychology and Anthropology, 36(1), 1-22. https://doi.org/10.1111/j.15481352.2008.00001.x.Bruner

28. PASTORE, S., \& PENTASSUGliA, M. (2015). Teaching as dance: A case-study for teacher practice analysis. International Journal of Educational Research, 70, 16-30. https://doi.org/10.1016/j.ijer.2014.12.001

29. RABATINI, V. (2010). A concepção de cultura em Bruner e Vigotski: implicações para a educação escolar. São Paulo.

30. SÖÖT, A., \& VISKUS, E. (2014). Contemporary Approaches to Dance Pedagogy - The Challenges of the 21st Century. Procedia - Social and Behavioral Sciences, 112(Iceepsy 2013), 290-299. https://doi.org/10.1016/j.sbspro.2014.01.1167

31. VIEIRA, A. (2013). Educação social e mediação sociocultural. (Profedições, Ed.) (1a). Porto.

32. XAVIER, M. (2017). Processos de Criação Coreográfica Contemporânea em Portugal: uma proposta de intervenção artístico-pedagógica. Universidade de Lisboa.

\section{Angelo Cid Neto}

Integrou, como bailarino, a Amálgama Companhia de Dança. Participou como intérprete em trabalhos de Willi Dorner, Marina Frangioia, Tiago Guedes, David Zambrano, João Fernandes entre outros. Integrou diversos festivais como performer e criador: Bienal de Veneza, Materiais Diversos, Metadança, Resolution! e Wbmotion. Colabora regularmente no projeto Compota - improvisação multidisciplinar com Paula Pinto. Colabora com o SAP Lab (Science Art and Philosophy) e integra o CIEBA (Centro de Investigação e de Estudos em Belas-Artes). Desenvolve um trabalho de criação artística dentro e fora dos contextos educativos com especial ênfase nas áreas transdisciplinares. É licenciado em Bioquímica (FCUL) e Dança (ESD), mestre em Artes Cénicas (FCSH) e Ensino de Dança (ESD). É doutorando em Educação Artística (IE\&FBAUL) onde desenvolve um trabalho de investigação na área da criação coreográfica em contextos educativos. É professor adjunto convidado na Escola Superior de Dança do Instituto Politécnico de Lisboa. 
Como citar este documento:

CID NETO, Angelo. PARA UMA CRIAÇÃO (EM) COMUM: PERSPETIVA SOCIO-CONSTRUTIVISTA PARA A CRIAÇÃO COREOGRÁFICA EM CONTEXTOS EDUCATIVOS. Reflexão e Ação, Santa Cruz do Sul, v. 29, n. 1, p. 151-168, jan. 2021. ISSN 1982-9949. Acesso em: doi: http://dx.doi.org/10.17058/rea.v29i1.14304 